\title{
The Relationship between Impulsivity and Quality of Life in Euthymic Patients with Bipolar Disorder
}

\author{
Yoon-Seok Kim ${ }^{1}$, Boseok Cha' ${ }^{1,2} \bowtie$, Dongyun Lee ${ }^{3}$, Sun-Mi Kim', Eunsoo Moon ${ }^{4}$, \\ Chul-Soo Park ${ }^{1,2}$, Bong-Jo Kim ${ }^{1,2}$, Cheol-Soon Lee ${ }^{1,2}$ and Sojin Lee Le, $^{1,2}$ \\ 1'Department of Psychiatry, Gyeongsang National University Hospital, Jinju, Republic of Korea \\ ${ }^{2}$ Department of Psychiatry, Gyeongsang National University College of Medicine, Jinju, Republic of Korea \\ ${ }^{3}$ Medical Unit of 9th Division, Korea Army, Goyang, Republic of Korea \\ ${ }^{4}$ Department of Psychiatry, Pusan National University Hospital Medical Research Institute, Busan, Republic of Korea
}

Objective Bipolar disorder (BD) is characterized by elevated impulsivity, even during periods of remission. Many recovered BD patients have functional impairments, which can lead to poor quality of life (QoL). The aim of this study was to investigate the association between impulsivity and QoL in euthymic BD patients.

Methods A total of 56 remitted or recovered patients with type I or II BD, diagnosed based on Diagnostic and Statistical Manual of Mental Disorders, Fourth Edition (DSM-IV) criteria, were recruited. Psychiatrists administered the Clinical Global Impression (CGI) for $\mathrm{BD}$ and the Global Assessment of Functioning (GAF) scales and then interviewed the subjects to assess clinical variables. Patients completed the Barratt Impulsiveness Scale (BIS-11) and the World Health Organization Quality of Life Assessment Instrument-Brief Form (WHOQoL-BREF). Pearson correlations, univariate regression analyses, and multiple linear regression analyses were performed.

Results The BIS-11 total score was significantly correlated with the WHOQoL-BREF total score $(r=-0.55, p<0.01)$ and with the WHOQoL-BREF subscales. After controlling for GAF score and other clinical variables, the BIS- 11 total score $(\beta=-0.43, p=0.001)$ was independently associated with overall QoL. Additionally, the BIS-11 total score was particularly strongly associated with the physical, psychological, and social domains of the multi-dimensional QoL scale.

Conclusion Our results suggest that high impulsivity is related to low QoL in euthymic BD patients. Further studies are needed to examine whether interventions for high impulsivity effectively improve QoL in patients with BD. Psychiatry Investig 2013;10:246-252

Key Words Bipolar disorder, Impulsivity, Quality of life.

\section{INTRODUCTION}

Bipolar disorder (BD) is a chronic mental illness characterized by recurring episodes of depression and mania or hypomania. The World Health Organization (WHO) labeled BD as one of 10 major causes of disability. ${ }^{1}$ The functional recovery rate is less than $50 \%$ for patients suffering from $\mathrm{BD}$, even when considering individuals in remission. ${ }^{2-4}$ Patients with BD report lower quality of life (QoL) when compared with patients with other medical conditions, including asthma, obesity,

Received: December 22, 2012 Revised: March 15, 2013

Accepted: March 27, 2013 Available online: September 16, 2013

$\triangle$ Correspondence: Boseok Cha, MD, PhD

Department of Psychiatry, Gyeongsang National University Hospital, 79 Gangnam-ro, Jinju 660-702, Republic of Korea

Tel: +82-55-750-8082, Fax: +82-55-759-0003, E-mail: cbs324@gmail.com

(c) This is an Open Access article distributed under the terms of the Creative Commons Attribution Non-Commercial License (http://creativecommons.org/licenses/bync/3.0) which permits unrestricted non-commercial use, distribution, and reproduction in any medium, provided the original work is properly cited. and chronic back pain..$^{5-8}$

QoL is a concept that encompasses various domains and includes physical, psychological, functional, social, economic, and vocational factors. ${ }^{9}$ The QoL of patients with BD is more impaired during depressive than manic or hypomanic episodes. ${ }^{8}$ Even for remitted BD patients, the physical, mental, social, and environmental aspects of QoL are impaired. ${ }^{10,11} \mathrm{Re}$ cently, efforts to treat BD have targeted improving the level of functional recovery and QoL rather than ameliorating isolated symptoms as important goals. ${ }^{8}$

To achieve these goals, it is important to identify factors that affect BD patients' QoL. Demographic and clinical characteristics that contribute to poor QoL include prolonged illness duration, ${ }^{5}$ young age of onset, ${ }^{12}$ being female, ${ }^{13}$ history of suicide attempts, ${ }^{14}$ poor insight, ${ }^{11}$ high nicotine dependence, ${ }^{15}$ absence of a social support system, ${ }^{15}$ comorbid alcohol dependence, ${ }^{16}$ comorbid anxiety disorders, ${ }^{17}$ numerous previous depressive episodes, ${ }^{18,19}$ and an extended undiagnosed period. ${ }^{20}$ 
Residual depressive symptoms are also associated with poor QoL. ${ }^{6}$ Additionally, Victor et al. ${ }^{21}$ reported that elevated impulsivity among patients with $\mathrm{BD}$ type $\mathrm{I}(\mathrm{BD}-\mathrm{I})$ is associated with poor QoL. However, their study was limited because of their inclusion of patients with $\mathrm{BD}$ who were not in remission.

Impulsivity can be defined as a tendency toward quick, unplanned reactions to any stimulus without considering the negative consequences of those reactions.2. Impulsivity is one of the diagnostic criteria for hypomanic or manic episodes as defined by the Diagnostic and Statistical Manual of Mental Disorders, Fourth Edition (DSM-IV). ${ }^{23}$ Elevated impulsivity is more frequently observed in $\mathrm{BD}$ patients than in the general population. ${ }^{24,25}$ Elevated impulsivity is not only related to suicide attempts and drug abuse among patients with $\mathrm{BD}$ but can also cause functional impairment. ${ }^{26-28}$ Furthermore, impulsivity remains high in $\mathrm{BD}$ patients even during remission. . $^{24-26,29-32}$ Therefore, elevated impulsivity may be a trait characteristic rather than a state characteristic of patients with $\mathrm{BD} .^{25}$

The current study investigated the relationship between impulsivity and QoL in euthymic BD patients. This study also examined which clinical variables, including impulsivity, contribute to poor QoL in BD patients.

\section{METHODS}

\section{Participants}

Patients with $\mathrm{BD}$ enrolled in this study were inpatients or outpatients in the Department of Psychiatry of Gyeongsang National University Hospital from May 2009 to December 2011. Psychiatrists diagnosed patients with BD according to DSM-IV criteria ${ }^{23}$ using a non-structured clinical interview. The criteria for inclusion in this study were 1) BD-I or BD-II diagnosis; 2) age between 18 and 65 years; and 3) remitted or recovered at the time of enrollment. Exclusion criteria were 1) diagnosed organic mental disorder; 2) mental retardation; 3) lifetime/current personality disorder; 4) concurrent alcohol and/or other substance abuse/dependence; and 5) presence of any other serious medical condition. The Institutional Review Board of Gyeongsang National University Hospital approved this study (approval number GNUH201301011).

\section{Methods}

In this study, remitted or recovered BD patients were recruited. The definition of remission or symptomatic recovery was based on the International Society for Bipolar Disorders (ISBD) Task Force report on the nomenclature of course and outcome in bipolar disorders. ${ }^{33}$ For inpatient participants, the Clinical Global Impression (CGI) assessment was administered weekly, and remission status was defined as a CGI score $\leq 2$ for at least 2 weeks. ${ }^{33}$ For outpatient participants, symp- tomatic recovery was defined as a CGI score $\leq 2$ for at least 2 months. ${ }^{33}$ Because inpatient participants are discharged from the hospital as soon as possible after remission from the acute episode of depression or mania, we could not recruit inpatient participants who had been in remission for at least 2 months, which was the criterion for outpatient participants. For this reason, we used different cutoffs for inpatient and outpatient participants with regard to remission of and recovery from BD. A total of 56 patients, 35 inpatients and 21 outpatients, were selected to participate in the study. All participants completed the Barratt Impulsiveness Scale (BIS) and the World Health Organization Quality of Life Assessment Instrument-Brief Form (WHOQoL-BREF). The Young Mania Rating Scale (YMRS) was used to assess manic or hypomanic symptoms. Semi-structured interviews were conducted to assess age of $\mathrm{BD}$ onset, number of past mood episodes, number of hospitalizations, family history, and presence of past psychotic symptoms.

\section{Measures}

\section{BIS}

The BIS was developed in 1959 to assess impulsivity. This test consists of three subscales ${ }^{34}:$ 1) Attention Impulsivity, 2) Motor Impulsivity, and 3) Non-planning Impulsivity. The BIS11 used in this study consisted of 30 questions from the eleventh edition of the scale. Total BIS scores generally range from 50 to 60 in healthy controls. ${ }^{35-37}$ The BIS-11 was translated into Korean by the authors. Because the BIS-11 Korean Translated Version was not verified for validity and reliability, internal coherence and test-retest reliability were assessed for the current study (22 respondents, average of 7 weeks in the test-retest period). The Cronbach's alpha coefficient was 0.77 , and the intraclass correlations between test and retest scores for all of the individual items were statistically significant.

\section{WHOQoL-BREF}

To create a transculturally applicable QoL rating scale, the WHO created the WHOQoL-100 through contributions from 15 international centers. ${ }^{38} \mathrm{~A}$ shortened version of the WHOQoL-100 was developed for ease of application in clinical practice. Although an abridged version, this scale was created to properly assess the various QoL dimensions. ${ }^{39}$ The WHOQoL-BREF scale consists of 26 questions covering physical health (seven items), psychological health (six items), social functioning (three items), and environmental domains (eight items). A higher score indicates better QoL. The WHOQoLBREF has been used in several studies assessing QoL among $\mathrm{BD}$ patients. ${ }^{40} \mathrm{Q}$ QL total scores generally range from 3.18 to 3.78 in healthy controls. ${ }^{16,41}$ The reliability and validity of this 
scale using Korean samples have been confirmed. ${ }^{42}$

\section{Statistical analyses}

Pearson correlation analyses were performed to assess the relationship between QoL total and subscale scores and various clinical variables including age, years of education, impulsivity, duration of illness, age of onset, number of past depressive episodes, number of hospitalizations, GAF score, and CGI score. Univariate regression analyses were performed to assess the relationship between QoL total and subscale scores, on the one hand, and each clinical variable, including BD subtype and history of suicide attempts, on the other. Significant variables from the correlation and univariate regression analyses ( $p$-value $<0.20$ ), together with age, gender, and CGI score, were used as independent variables, and QoL total and subscale scores were treated as dependent variables in the multiple linear regression analysis. All statistics were analyzed using PASW Statistics version 18.0 (Chicago, IL, USA). In all cases, a two-tailed $p$-value $<0.05$ was considered statistically significant.

\section{RESULTS}

\section{Demographic and clinical characteristics}

Participants' sociodemographic and clinical characteristics are presented in Table 1 . The average total impulsivity score was $61.48(\mathrm{SD}=8.95)$; the average subscale scores were 14.57 ( $\mathrm{SD}=3.64)$ for attention impulsivity, 20.46 ( $\mathrm{SD}=3.80)$ for motor impulsivity, and 26.45 ( $\mathrm{SD}=5.18$ ) for non-planning impulsivity. Based on the WHOQoL-BREF scale, the average QoL total score was $3.25(\mathrm{SD}=0.58)$, and the individual subdomain average scores were 24.21 for physical QoL $(\mathrm{SD}=4.54)$, 19.27 for psychological QoL ( $\mathrm{SD}=3.99)$, 9.23 for social QoL $(\mathrm{SD}=2.30)$, and 25.25 for environmental QoL $(\mathrm{SD}=5.65)$.

\section{Association of clinical variables with QoL}

As shown in Table 2, QoL total scores were significantly associated with length of education $(\mathrm{r}=0.374, \mathrm{p}=0.005)$, GAF score $(r=0.509, p<0.001)$, CGI score $(r=-0.283, p=0.034)$, total BIS score ( $\mathrm{r}=-0.550, \mathrm{p}<0.001)$ (Figure 1 ), and scores on all impulsivity subscales. Regarding the QoL subdomains of the WHOQoL-BREF, physical QoL was significantly associated with length of education $(r=0.396, p=0.003)$, GAF score $(r=$ $0.461, \mathrm{p}<0.001)$, CGI score $(\mathrm{r}=-0.288, \mathrm{p}=0.032)$, total BIS score $(\mathrm{r}=-0.568, \mathrm{p}<0.001)$ and scores on all impulsivity subscales. Psychological QoL was significantly correlated with length of education ( $r=0.307, p=0.022)$, GAF score $(r=0.484, p<0.001)$, total BIS score $(\mathrm{r}=-0.550, \mathrm{p}<0.001)$ and scores on all impulsivity subscales. Social QoL was significantly related to number of hospitalizations ( $\mathrm{r}=-0.271, \mathrm{p}=0.048)$, GAF score $(\mathrm{r}=0.324, \mathrm{p}=$ $0.015)$, total BIS score $(\mathrm{r}=-0.345, \mathrm{p}=0.009)$, attention impul-
Table 1. Demographic and clinical characteristics

\begin{tabular}{|c|c|}
\hline Variables & $\begin{array}{l}\text { Whole sample } \\
\qquad(\mathrm{N}=56)\end{array}$ \\
\hline Age (mean, SD), years & $36.79(11.26)$ \\
\hline Male (N, \%) & $24(42.9)$ \\
\hline Length of education (mean, SD), years & $13.29(2.46)$ \\
\hline \multicolumn{2}{|l|}{ Marital status (N, \%) } \\
\hline Single/Never married & $22(39.3)$ \\
\hline Married/Cohabitation & $30(53.6)$ \\
\hline Separated/Divorced/Widowed & $4(7.1)$ \\
\hline Employment status (employed) (N, \%) & $44(78.6)$ \\
\hline \multicolumn{2}{|l|}{ First episode polarity (N, \%) } \\
\hline Mania/Hypomania & $30(58.8)$ \\
\hline Depression & $19(37.3)$ \\
\hline $\begin{array}{l}\text { Major mood episode age of onset } \\
\text { (mean, SD), years }\end{array}$ & $28.16(9.81)$ \\
\hline $\begin{array}{l}\text { Total number of major depressive episodes } \\
(\text { mean, SD) }\end{array}$ & $1.77(1.85)$ \\
\hline Number of hospitalizations (mean, SD) & $2.56(2.93)$ \\
\hline Family history of mental disorder (yes) (N, \%) & $35(67.3)$ \\
\hline Psychotic symptoms with mood episode (N, \%) & $32(66.7)$ \\
\hline Suicide attempt history (N, \%) & $10(18.9)$ \\
\hline \multicolumn{2}{|l|}{ Diagnosis $(\mathrm{N}, \%)$} \\
\hline Bipolar disorder type I & $38(67.9)$ \\
\hline Bipolar disorder type II & $18(32.1)$ \\
\hline BIS (total) (mean, SD) & $61.48(8.95)$ \\
\hline WHOQoL-BREF (total) (mean, SD) & $3.25(0.58)$ \\
\hline GAF (mean, SD) & $75.18(7.98)$ \\
\hline CGI-S (mean, SD) & $1.57(0.50)$ \\
\hline YMRS (mean, SD) & $3.77(2.98)$ \\
\hline
\end{tabular}

BIS: Barratt Impulsiveness Scale, WHOQoL-BREF: World Health Organization Quality of Life Assessment Instrument-Brief Form, GAF: Global Assessment of Functioning, CGI: Clinical Global Impression, YMRS: Young Mania Rating Scale

sivity ( $r=-0.307, \mathrm{p}=0.021$ ), and motor impulsivity $(\mathrm{r}=-0.280$, $\mathrm{p}=0.036)$. Environmental QoL was related to length of education $(r=0.320, p=0.016)$, number of hospitalizations $(r=-0.330$, $\mathrm{p}=0.015)$, GAF score $(\mathrm{r}=0.411, \mathrm{p}=0.002)$, total BIS score $(\mathrm{r}=$ $-0.360, p=0.006)$ and non-planning impulsivity $(r=-0.310, p=$ $0.020)$. History of suicide attempts had a marginally significant association with psychological $\mathrm{QoL}(\mathrm{F}=3.816, \mathrm{df}=1, \mathrm{p}=$ 0.056 , adjusted $R^{2}=0.051$ ) in the univariate regression analysis. In a separate univariate regression analysis, $\mathrm{BD}$ subtype had a statistically nonsignificant relationships to physical $\left(\mathrm{F}=2.523, \mathrm{df}=1, \mathrm{p}=0.118\right.$, adjusted $\left.\mathrm{R}^{2}=0.027\right)$, psychological $\left(\mathrm{F}=2.512, \mathrm{df}=1, \mathrm{p}=0.119\right.$, adjusted $\left.\mathrm{R}^{2}=0.027\right)$, social $(\mathrm{F}=0.021$, $\mathrm{df}=1, \mathrm{p}=0.885$, adjusted $\left.\mathrm{R}^{2}=-0.018\right)$, and environmental $(\mathrm{F}=$ $0.877, \mathrm{df}=1, \mathrm{p}=0.353$, adjusted $\mathrm{R}^{2}=-0.002$ ) QoL. 
Table 2. Correlations between World Health Organization Quality of Life Assessment Instrument-Brief Form (WHOQoL-BREF) and clinical variables

\begin{tabular}{lccccc}
\hline & \multicolumn{3}{c}{ WHOQoL-BREF } \\
\cline { 2 - 6 } & Total & Physical & Psychological & Social & Environmental \\
\hline Age & -0.023 & -0.040 & 0.074 & -0.103 & -0.044 \\
Length of education & $0.374^{* *}$ & $0.396^{* *}$ & $0.307^{*}$ & 0.178 & $0.320^{*}$ \\
Number of hospitalizations & -0.201 & -0.042 & -0.042 & $-0.271^{*}$ & $-0.330^{*}$ \\
Total number of MDEs & -0.180 & -0.150 & -0.195 & -0.115 & -0.084 \\
Duration of illness & -0.038 & 0.035 & 0.094 & -0.117 & -0.157 \\
Major mood episode onset age & 0.046 & -0.056 & 0.050 & 0.028 & 0.112 \\
GAF score & $0.509^{* *}$ & $0.461^{* *}$ & $0.484^{* *}$ & $0.324^{*}$ & $0.411^{* *}$ \\
CGI score & $-0.283^{*}$ & $-0.288^{*}$ & -0.215 & -0.165 & -0.200 \\
BIS, total & $-0.550^{* *}$ & $-0.568^{* *}$ & $-0.550^{* *}$ & $-0.345^{* *}$ & $-0.360^{* *}$ \\
$\quad$ Attention & $-0.456^{* *}$ & $-0.535^{* *}$ & $-0.456^{* *}$ & $-0.307^{*}$ & -0.240 \\
Motor & $-0.345^{* *}$ & $-0.371^{* *}$ & $-0.367^{* *}$ & $-0.280^{*}$ & -0.195 \\
$\quad$ Non-planning & $-0.376^{* *}$ & $-0.335^{*}$ & $-0.362^{* *}$ & -0.175 & $-0.310^{*}$ \\
\hline
\end{tabular}

${ }^{*} \mathrm{p}<0.05,{ }^{* *} \mathrm{p}<0.01$. MDE: Major Depressive Episode, GAF: Global Assessment of Functioning, BIS: Barratt Impulsiveness Scale, CGI: Clinical Global Impression

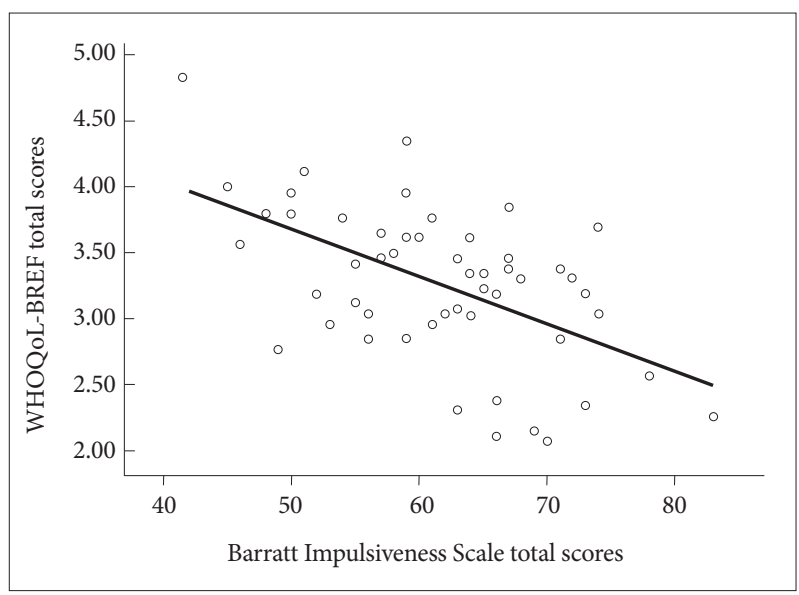

Figure 1. Correlation between the World Health Organization Quality of Life Assessment Instrument-Brief Form (WHOQoL-BREF) and the Barratt Impulsiveness Scale (BIS) scores.

\section{Multiple linear regression models between clinical variables and QoL}

Clinical variables that had significant associations with the QoL total and/or subdomain scores according to the Pearson correlation and univariate regression analyses ( $\mathrm{p}$-value $<0.20$ ), together with age, gender, and CGI score, were used in the multiple linear regression analyses. First, the QoL total score was used as the dependent variable; age, gender, years of education, total BIS score, GAF score, CGI score, and number of hospitalizations were entered as independent variables. Only the total BIS score $(\beta=-0.43, \mathrm{p}=0.001)$ was predictive of the QoL total score, explaining $41.5 \%$ of the variance in $\mathrm{QoL}(\mathrm{F}=$ $6.368, \mathrm{df}=7, \mathrm{p}<0.001$, adjusted $\mathrm{R}^{2}=0.415$ ). In a separate analysis, we used physical QoL as a dependent variable. Age, gender, years of education, total BIS score, GAF score, CGI score and $\mathrm{BD}$ subtype were used in this second model. Again, only the total BIS score $(\beta=-0.50, p=0.001)$ was predictive of physical QoL, explaining $41.8 \%$ of the variance in physical QoL $\left(\mathrm{F}=6.632, \mathrm{df}=7, \mathrm{p}<0.001\right.$, adjusted $\left.\mathrm{R}^{2}=0.418\right)$. Then, psychological QoL was entered as the dependent variable in a separate regression analysis. Age, gender, years of education, total BIS score, GAF score, CGI score, BD subtype, number of past depressive episodes, and history of past suicide attempts were entered as independent variables. Only the total BIS score $(\beta=$ $-0.38, \mathrm{p}=0.010$ ) was predictive of psychological QoL, explaining $24.9 \%$ of the variance in the psychological $\mathrm{QoL}(\mathrm{F}=2.883$, $\mathrm{df}=9, \mathrm{p}=0.010$, adjusted $\mathrm{R}^{2}=0.249$ ). Next, social QoL was entered as the dependent variable, and age, gender, years of education, total BIS score, GAF score, CGI score, and number of hospitalizations were entered as independent variables in a separate regression analysis. Once more, only the total BIS $(\beta=-0.29, p=0.047)$ score was predictive of social $\mathrm{QoL}$, explaining $17.4 \%$ of the variance in the social $\mathrm{QoL}(\mathrm{F}=2.592, \mathrm{df}=$ 7 , $\mathrm{p}=0.024$, adjusted $\mathrm{R}^{2}=0.174$ ). Finally, environmental QoL was entered as the dependent variable, with age, gender, years of education, total BIS score, GAF score, CGI score, and number of hospitalizations entered as independent variables in the last regression model. Here, only the number of hospitalizations ( $\beta=-0.29, \mathrm{p}=0.029)$ was predictive of the environmental QoL, explaining $25.3 \%$ of the variance in the environmental QoL ( $\mathrm{F}=3.568, \mathrm{df}=7, \mathrm{p}=0.004$, adjusted $\mathrm{R}^{2}=0.253$ ).

\section{DISCUSSION}

The current study explored the relationships of multiple clinical variables, including impulsivity, to QoL among remit- 
ted or recovered patients with $\mathrm{BD}$. The main findings of this study are as follows. First, high impulsivity was associated with low QoL across euthymic BD patients. Additionally, three impulsivity subscales were all significantly related to QoL. Second, despite controlling for overall functioning and several factors associated with QoL, impulsivity was independently associated with QoL. Third, impulsivity, along with physical, psychological, and social domains of a multi-dimensional QoL scale, were particularly relevant.

In this study, the impulsivity total score was related to the QoL total score and to the three QoL subdomains. In our multiple regression analyses, impulsivity was predictive of physical, psychological, and social domains of QoL. These results are consistent with results from previous studies. ${ }^{21}$ It must be noted that the influence of mood symptoms was minimized in the current study because the target subjects were patients in remission or recovery.

Recent studies of patients with BD demonstrated that elevated impulsivity was associated with overall functional impairment. ${ }^{28}$ This functional impairment has the potential to affect QoL among patients with BD. However, the current study showed that even when overall level of functioning was controlled, high impulsivity was independently related to QoL and subdomains of QoL. In other words, impulsivity can influence QoL through mechanisms distinct from functional impairment. Therefore, the results of the current study suggest that to improve QoL among patients with $\mathrm{BD}$, it is not only necessary to restore functioning but also to control elevated impulsivity. However, the current study did not evaluate the level of functioning across a variety of areas. Instead, we used a single functional assessment tool, namely the GAF. The GAF might be influenced by symptoms as well as by the level of functioning. If symptoms are not evident, GAF sensitivity might be lower. Future research is needed to investigate whether impulsivity has an independent effect on QoL after controlling for the level of functioning across a variety of areas.

Many studies have suggested that patients with BD show neurocognitive impairments in sustained attention, verbal memory, and executive functioning not only during acute mood episodes but also during euthymia. ${ }^{43-48}$ In this study, the impulsivity subscale of an attentional measure showed a significant negative correlation with almost all QoL subdomains. Given that attentional impulsivity, a subscale of the BIS-11, involves a tendency to shift attention quickly, ${ }^{34}$ our results support previous findings that neurocognitive impairment is associated with poor psychosocial functioning and lower QoL in patients with $\mathrm{BD} .{ }^{49,50}$

Regarding the correlations between the subscales of impulsivity and the subdomains of QoL, both the physical and psychological domains of QoL were related to the three sub- scales of impulsivity, and the social domain of QoL was related to the two subscales of impulsivity. In contrast, the environmental domain of QoL was related to only one impulsivity subscale. Furthermore, the regression analysis did not reveal a significant association between the environmental domain and impulsivity. This suggests that the influence of impulsivity is least evident in the environmental domain of QoL. It is not surprising that the psychological domain, which reflects positive/negative thoughts, self-esteem, body image, and personal beliefs, would be more closely related to impulsivity than would the environmental domain. Additionally, decreased psychological QoL was reported in patients with BD and comorbid substance dependence, ${ }^{16}$ which is directly related to impulsivity. ${ }^{26}$ Therefore, the results of the current study suggest that the specific predictors of the environmental QoL subdomain are likely quite different from those of the other QoL subdomains. Further research is warranted to replicate this finding.

Most of the known associated demographic and clinical variables were not related to QoL in our sample. However, impulsivity and number of hospitalizations did contribute to QoL. Demographic variables such as gender and age were not related to QoL; these findings are congruent with previous research. ${ }^{10}$ The age of onset and duration of illness were not related to QoL. The average age of onset for subjects in this study was 28.16 years $(\mathrm{SD}=9.81)$, relatively older than the known age of onset for $\mathrm{BD} .{ }^{51}$ Using the age of onset for major mood episodes, rather than the age at which mood-related symptoms first appeared, would have probably affected the results of the current study. However, as a previous study suggested that age of onset and duration of illness were not associated with QoL, ${ }^{10}$ further studies are needed to examine how age of onset and duration of illness are related to QoL in more detail.

The current study had some limitations. First, because our patients were recruited at a tertiary university hospital, generalizing our results to other BD samples may be difficult. Second, recall bias may have occurred as a result of using a retrospective method to evaluate the age of onset, the number of mood episodes, and other clinical variables. Third, the limited number of participants may have affected the statistical validity of our results. Fourth, outpatient participants were in remission for at least 2 months, whereas inpatient participants were in remission for at least 2 weeks. Thus, in some cases, especially for hospitalized patients, the influence of subsyndromal mood symptoms on impulsivity and QoL cannot be completely ruled out. In this study, however, we minimized the influence of subsyndromal symptoms by controlling the CGI score in the multiple linear regression analyses. Fifth, Axis I and II disorders were diagnosed using non-structured clinical interviews instead of the structured clinical interview for DSM-IV Axis I and II (SCID-I, SCID-II). 
Despite these limitations, one strength of this study was our observation of a relationship between impulsivity and QoL in remitted and recovered patients with BD. Additionally, impulsivity was independently associated with QoL even after controlling for several variables previously shown to affect QoL among patients with $\mathrm{BD}$. Our findings suggest that clinicians should assess the impulsivity of BD patients in routine clinical practice.

In the future, treatment for bipolar disorder should focus on improving QoL rather than simply on improving mood symptoms. ${ }^{52}$ To improve QoL, treatment programs must be developed to properly manage patients' impulsivity. Furthermore, additional research is needed to test whether regulating or adequately controlling impulsivity will improve patients' QoL.

\section{REFERENCES}

1. Mathers C, Fat DM, Boerma J. The Global Burden of Disease: 2004 Update. Geneva: World Health Organization; 2008.

2. Rosa AR, Franco C, Martinez-Aran A, Sanchez-Moreno J, Reinares M, Salamero M, et al. Functional impairment in patients with remitted bipolar disorder. Psychother Psychosom 2008;77:390-392.

3. Goetz I, Tohen M, Reed C, Lorenzo M, Vieta E, EMBLEM Advisory Board. Functional impairment in patients with mania: baseline results of the EMBLEM study. Bipolar Disord 2007;9:45-52.

4. Strakowski SM, Williams JR, Fleck DE, Delbello MP. Eight-month functional outcome from mania following a first psychiatric hospitalization. J Psychiatr Res 2000;34:193-200.

5. Robb JC, Cooke RG, Devins GM, Young LT, Joffe RT. Quality of life and lifestyle disruption in euthymic bipolar disorder. J Psychiatr Res 1997;31:509-517.

6. Vojta C, Kinosian B, Glick H, Altshuler L, Bauer MS. Self-reported quality of life across mood states in bipolar disorder. Compr Psychiatry 2001;42:190-195.

7. ten Have M, Vollebergh W, Bijl R, Nolen WA. Bipolar disorder in the general population in The Netherlands (prevalence, consequences and care utilisation): results from The Netherlands Mental Health Survey and Incidence Study (NEMESIS). J Affect Disord 2002;68:203-213.

8. IsHak WW, Brown K, Aye SS, Kahloon M, Mobaraki S, Hanna R. Health-related quality of life in bipolar disorder. Bipolar Disord 2012; 14:6-18.

9. Cramer JA, Rosenheck R, Xu W, Thomas J, Henderson W, Charney DS. Quality of life in schizophrenia: a comparison of instruments. Department of Veterans Affairs Cooperative Study Group on Clozapine in Refractory Schizophrenia. Schizophr Bull 2000;26:659-666.

10. Sierra P, Livianos L, Rojo L. Quality of life for patients with bipolar disorder: relationship with clinical and demographic variables. Bipolar Disord 2005;7:159-165.

11. Dias VV, Brissos S, Frey BN, Kapczinski F. Insight, quality of life and cognitive functioning in euthymic patients with bipolar disorder. J Affect Disord 2008;110:75-83.

12. Perlis RH, Miyahara S, Marangell LB, Wisniewski SR, Ostacher M, DelBello MP, et al. Long-term implications of early onset in bipolar disorder: data from the first 1000 participants in the systematic treatment enhancement program for bipolar disorder (STEP-BD). Biol Psychiatry 2004;55:875-881.

13. Robb JC, Young LT, Cooke RG, Joffe RT. Gender differences in patients with bipolar disorder influence outcome in the medical outcomes survey (SF-20) subscale scores. J Affect Disord 1998;49:189-193.

14. de Abreu LN, Nery FG, Harkavy-Friedman JM, de Almeida KM, Gomes BC, Oquendo MA, et al. Suicide attempts are associated with worse quality of life in patients with bipolar disorder type I. Compr Psychiatry 2012;53:125-129.

15. Gutierrez-Rojas L, Gurpegui M, Ayuso-Mateos JL, Gutierrez-Ariza JA, Ruiz-Veguilla M, Jurado D. Quality of life in bipolar disorder patients: a comparison with a general population sample. Bipolar Disord 2008; 10:625-634.

16. Singh J, Mattoo SK, Sharan P, Basu D. Quality of life and its correlates in patients with dual diagnosis of bipolar affective disorder and substance dependence. Bipolar Disord 2005;7:187-191.

17. Albert U, Rosso G, Maina G, Bogetto F. Impact of anxiety disorder comorbidity on quality of life in euthymic bipolar disorder patients: differences between bipolar I and II subtypes. J Affect Disord 2008;105: 297-303.

18. MacQueen GM, Young LT, Robb JC, Marriott M, Cooke RG, Joffe RT. Effect of number of episodes on wellbeing and functioning of patients with bipolar disorder. Acta Psychiatr Scand 2000;101:374-381.

19. Fenn HH, Bauer MS, Altshuler L, Evans DR, Williford WO, Kilbourne $\mathrm{AM}$, et al. Medical comorbidity and health-related quality of life in bipolar disorder across the adult age span. J Affect Disord 2005;86:47-60.

20. Gazalle FK, Andreazza AC, Cereser KM, Hallal PC, Santin A, Kapczinski F. Clinical impact of late diagnose of bipolar disorder. J Affect Disord 2005;86:313-316.

21. Victor SE, Johnson SL, Gotlib IH. Quality of life and impulsivity in bipolar disorder. Bipolar Disord 2011;13:303-309.

22. Moeller FG, Barratt ES, Dougherty DM, Schmitz JM, Swann AC. Psychiatric aspects of impulsivity. Am J Psychiatry 2001;158:1783-1793.

23. American Psychiatric Association. Diagnostic and Statistical Manual of Mental Disorders, Fourth Edition. Washington, DC: American Psychiatric Association; 1994.

24. Peluso MA, Hatch JP, Glahn DC, Monkul ES, Sanches M, Najt P, et al. Trait impulsivity in patients with mood disorders. J Affect Disord 2007; 100:227-231.

25. Ekinci O, Albayrak Y, Ekinci AE, Caykoylu A. Relationship of trait impulsivity with clinical presentation in euthymic bipolar disorder patients. Psychiatry Res 2011;190:259-264.

26. Swann AC, Dougherty DM, Pazzaglia PJ, Pham M, Moeller FG. Impulsivity: a link between bipolar disorder and substance abuse. Bipolar Disord 2004;6:204-212.

27. Perroud N, Baud P, Mouthon D, Courtet P, Malafosse A. Impulsivity, aggression and suicidal behavior in unipolar and bipolar disorders. J Affect Disord 2011;134:112-118.

28. Jimenez E, Arias B, Castellvi P, Goikolea JM, Rosa AR, Fananas L, et al. Impulsivity and functional impairment in bipolar disorder. J Affect Disord 2012;136:491-497.

29. Swann AC, Anderson JC, Dougherty DM, Moeller FG. Measurement of inter-episode impulsivity in bipolar disorder. Psychiatry Res 2001; 101:195-197.

30. Swann AC, Pazzaglia P, Nicholls A, Dougherty DM, Moeller FG. Impulsivity and phase of illness in bipolar disorder. J Affect Disord 2003; 73:105-111.

31. Swann AC, Lijffijt M, Lane SD, Steinberg JL, Moeller FG. Increased traitlike impulsivity and course of illness in bipolar disorder. Bipolar Disord 2009;11:280-288.

32. Strakowski SM, Fleck DE, DelBello MP, Adler CM, Shear PK, Kotwal R, et al. Impulsivity across the course of bipolar disorder. Bipolar Disord 2010;12:285-297.

33. Tohen M, Frank E, Bowden CL, Colom F, Ghaemi SN, Yatham LN, et al. The International Society for Bipolar Disorders (ISBD) Task Force report on the nomenclature of course and outcome in bipolar disorders. Bipolar Disord 2009;11:453-473.

34. Patton JH, Stanford MS, Barratt ES. Factor structure of the Barratt impulsiveness scale. J Clin Psychol 1995;51:768-774.

35. Lee SR, Lee WH, Park JS, Kim SM, Kim JW, Shim JH. The study on Reliability and Validity of Korean Version of the Barratt Impulsiveness Scale-11-Revised in nonclinical adult subjects. J Korean Neuropsychiatr 
Assoc 2012;51:378-386.

36. Lewis M, Scott J, Frangou S. Impulsivity, personality and bipolar disorder. Eur Psychiatry 2009;24:464-469.

37. Swann AC, Bjork JM, Moeller FG, Dougherty DM. Two models of impulsivity: relationship to personality traits and psychopathology. Biol Psychiatry 2002;51:988-994.

38. The World Health Organization Quality of Life Assessment (WHOQOL): development and general psychometric properties. Soc Sci Med 1998;46:1569-1585.

39. Development of the World Health Organization WHOQOL-BREF quality of life assessment. The WHOQOL Group. Psychol Med 1998; 28:551-558.

40. Michalak EE, Yatham LN, Lam RW. Quality of life in bipolar disorder: a review of the literature. Health Qual Life Outcomes 2005;3:72.

41. Park CM, Lee JR. Quality of life Using WHOQOL-BREF in Taegu. Korean J Health Policy Admin 2000;10:129-154.

42. Min SK, Lee CI, Kim KI, Suh SY, Kim DK. Development of Korean version of WHO Quality of Life Scale Abbreviated version (WHOQOLBREF). J Korean Neuropsychiatr Assoc 2000;39:571-579.

43. Martinez-Aran A, Vieta E, Reinares M, Colom F, Torrent C, SanchezMoreno J, et al. Cognitive function across manic or hypomanic, depressed, and euthymic states in bipolar disorder. Am J Psychiatry 2004;161: 262-270.

44. Robinson LJ, Thompson JM, Gallagher P, Goswami U, Young AH, Ferrier IN, et al. A meta-analysis of cognitive deficits in euthymic patients with bipolar disorder. J Affect Disord 2006;93:105-115.
45. Torres IJ, Boudreau VG, Yatham LN. Neuropsychological functioning in euthymic bipolar disorder: a meta-analysis. Acta Psychiatr Scand Suppl 2007;434:17-26.

46. Latalova K, Prasko J, Diveky T, Kamaradova D, Velartova H. Cognitive dysfunction, dissociation and quality of life in bipolar affective disorders in remission. Psychiatr Danub 2010;22:528-534.

47. Bonnin CM, Sanchez-Moreno J, Martinez-Aran A, Sole B, Reinares M, Rosa AR, et al. Subthreshold symptoms in bipolar disorder: impact on neurocognition, quality of life and disability. J Affect Disord 2012;136: 650-659.

48. Elshahawi HH, Essawi H, Rabie MA, Mansour M, Beshry ZA, Mansour AN. Cognitive functions among euthymic bipolar I patients after a single manic episode versus recurrent episodes. J Affect Disord 2011;130: 180-191.

49. Harvey PD, Wingo AP, Burdick KE, Baldessarini RJ. Cognition and disability in bipolar disorder: lessons from schizophrenia research. Bipolar Disord 2010;12:364-375.

50. Pattanayak RD, Sagar R, Mehta M. Neuropsychological performance in euthymic Indian patients with bipolar disorder type I: correlation between quality of life and global functioning. Psychiatry Clin Neurosci 2012;66:553-563.

51. Berk M, Dodd S, Callaly P, Berk L, Fitzgerald P, de Castella AR, et al. History of illness prior to a diagnosis of bipolar disorder or schizoaffective disorder. J Affect Disord 2007;103:181-186.

52. Michalak EE, Yatham LN, Kolesar S, Lam RW. Bipolar disorder and quality of life: a patient-centered perspective. Qual Life Res 2006;15:25-37. 